
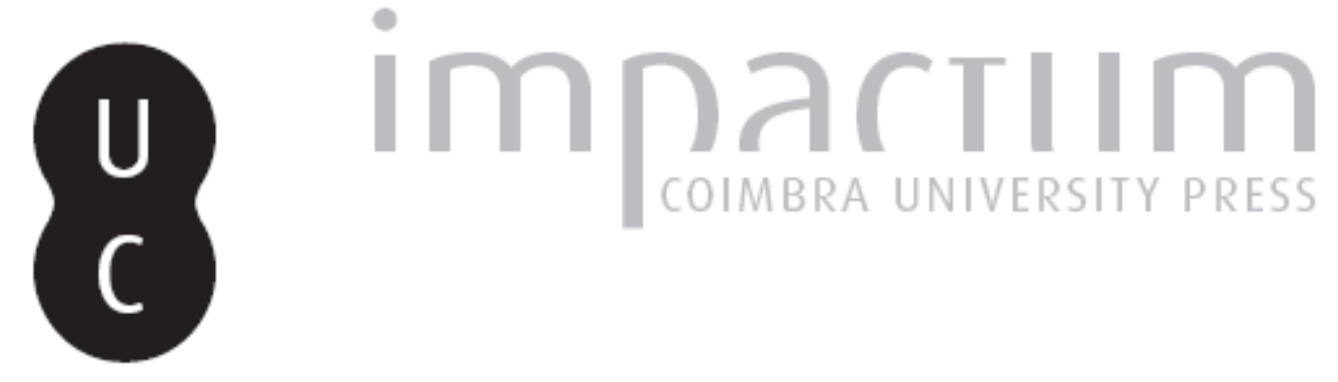

\title{
Paleoambiente y formación de los paisajes antiguos de la comarca de la Sierra de Francia (Salamanca, España): de la estructura social a la creación del paisaje
}

\author{
Autor(es): $\quad$ López Jiménez, Óscar; López Sáez, J. Antonio
}

Publicado por: Faculdade de Letras da Universidade de Coimbra

URL persistente:

URI:http://hdl.handle.net/10316.2/37807

DOI:

DOI:http://dx.doi.org/10.14195/1647-8657_44_1

Accessed : $\quad$ 26-Apr-2023 12:49:36

A navegação consulta e descarregamento dos títulos inseridos nas Bibliotecas Digitais UC Digitalis, UC Pombalina e UC Impactum, pressupõem a aceitação plena e sem reservas dos Termos e Condições de Uso destas Bibliotecas Digitais, disponíveis em https://digitalis.uc.pt/pt-pt/termos.

Conforme exposto nos referidos Termos e Condições de Uso, o descarregamento de títulos de acesso restrito requer uma licença válida de autorização devendo o utilizador aceder ao(s) documento(s) a partir de um endereço de IP da instituição detentora da supramencionada licença.

Ao utilizador é apenas permitido o descarregamento para uso pessoal, pelo que o emprego do(s) título(s) descarregado(s) para outro fim, designadamente comercial, carece de autorização do respetivo autor ou editor da obra.

Na medida em que todas as obras da UC Digitalis se encontram protegidas pelo Código do Direito de Autor e Direitos Conexos e demais legislação aplicável, toda a cópia, parcial ou total, deste documento, nos casos em que é legalmente admitida, deverá conter ou fazer-se acompanhar por este aviso.

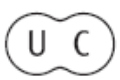




\section{CONIMBRIGA}

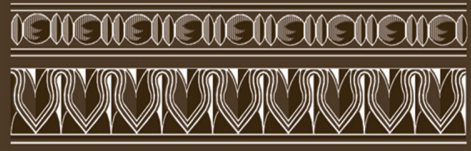

INSTITUTO DE ARQUEOLOGIA

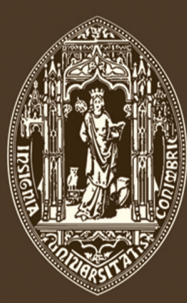

VOLUME XLIV • 2005

FACULDADE DE LETRAS UNIVERSIDADE DE COIMBRA 


\section{ÓSCAR LÓPEZ JIMÉNEZ}

Department of Archaeology. University of Reading (U.K.).

\section{J. ANTONIO LóPEZ SÁEZ}

Laboratorio de Palinología. Departamento de Prehistoria del Instituto de Historia del CSIC (España).

\section{PALEOAMBIENTE Y FORMACIÓN DE LOS PAISAJES ANTIGUOS DE LA COMARCA DE LA SIERRA DE FRANCIA (SALAMANCA, ESPAÑA): DE LA ESTRUCTURA SOCIAL A LA CREACIÓN DEL PAISAJE. "Conimbriga" XLIV (2005) p. 5-24}

SUMMARY: This work is consequence of a part of the results of the projects developed by the research team "Estructura Social y Territorio: Arqueología del Paisaje" of the CSIC in the region of Sierra de Francia, at the South of Salamanca. Through a series of selective test pits an important amount of palinology samples in stratigraphy have been recovered that allow the environmental characterization of three sites belonging to different stages of Proto-history sequence. These data, in relation to other series of samples, the analysis of the location's characteristics, the potential of exploitation, the morphology of the settlements or the characteristics of the topographic relations, allow the creation of accurate historical sequences where strong social transformations are recognized. These, in relation to the formation of the ancient landscapes, are very clear. The present work is, nowadays, a unique contribution in this aspect in the area. The analyses reveal three differentiated moments clearly in this sequence that imply forms of relation with means very different, supported by equally diverse social systems. From the moment of transition of the Late Bronze Age to the Early Iron Age, possibly around 9th to 8th Century b. C., we arrive to the re-structure of the territories in Roman times and the beginning of the systematic exploitation imposed to suit a tributary mode of production that seems to begin in this zone in the 2nd half of 1 st Century B. C. 
RESUMO: Neste trabalho apresenta-se uma parte dos resultados dos projetos desenvolvidos pela equipa de pesquisa "Estructura Social y Territorio: Arqueologia del Paisaje" do CSIC, na Comarca da Serra de Francia, ao sul da província de Salamanca.

Por meio de uma série de sondagens seletivas, foi recuperada uma quantidade suficiente de amostras palinológicas em estratigrafia, que permitem a caracterização ambiental de três sítios arqueológicos correspondentes a diferentes momentos da Proto-história. Ditos dados, relacionados com outras séries de amostras, com a análise das características locacionais, o potencial de aproveitamento do meio, a morfologia dos assentamentos ou as características das relações locacionais, permitem a criação de seqüências históricas onde são identificadas grandes transformações sociais. Estas transformações que se referem à formação das paisagens antigas, estão muitas claras e aportam uma referência, até agora, única na área.

As análises revelam três momentos bastante diferenciados na sequiência, o que sugere formas de relação com o meio muito diferentes, apoiadas por sistemas sociais igualmente diversos. Desde o momento de transição do Bronze Final até o Primeiro Ferro, possivelmente em torno aos séculos IX o VIII a.C., chegamos até a re-articulação dos territórios na época romana e o inicio da exploração sistemática, que ao parecer começa nesta área, aproximadamente na metade do século I a.C. 


\section{PALEOAMBIENTE Y FORMACIÓN DE LOS PAISAJES ANTIGUOS DE LA COMARCA DE LA SIERRA DE FRANCIA (SALAMANCA, ESPAÑA):}

De la estructura social a la creación del paisaje.

\section{La Secuencia Protohistórica de la Sierra de Francia}

El espacio aquí definido como la Comarca de la Sierra de Francia abarca una zona amplia del sector central - meridional de la provincia de Salamanca. En él se incluyen las Sierras de Francia, Quilamas, Tamames y La Alberca, así como los cursos altos de los ríos Yeltes, Morasverdes, Quilamas y Francia, además de numerosos arroyos (Est. I). Se trata de un área de cerca de $250 \mathrm{Km}^{2}$ donde se dan todos los ambientes biotópicos y geográficos representados en el resto de la zona Sudoccidental de la Meseta Norte. Geográficamente se caracteriza por una fuerte variabilidad de alturas que marcan un relieve escalonado. Desde un punto de vista geológico predominan los esquistos, grawacas y pizarras con intrusiones de granitos que afloran en diversos puntos. En las cotas más altas, las cuarcitas armoricanas marcan las crestas de las sierras. Los sedimentos plio-pleistocénicos se extienden en el piedemonte, más extensamente en esta vertiente del Duero que en la meridional de los fluentes del Tajo.

Las sierras proporcionan una vegetación variada y en las zonas del piedemonte se dan principalmente zonas de terreno rocoso. Actualmente la imagen que nos presenta esta área, cuando no ha sido repoblada con formaciones de pinos, es la de grandes extensiones pobladas por el rebollo (Quercus pyrenaica), especialmente en la umbría y los valles situados en los pies de sierra, con una cierta presencia de encina (Quercus ilex) y alcornoque (Quercus suber), siendo muy abundante el monte bajo en todo el área, que crea en ocasiones formaciones muy densas. Este monte bajo lo componen principalmente las jaras (Cistus lada- 
nifer y Cistus populifolius), escobas (Cytius scoparius), tomillo (Thimus sp.) o, en las zonas algo más húmedas, el brezo (Erica australis). Los valles, todavía encajados, de los ríos que nacen en estos lugares ofrecen espacios no muy abundantes pero sí muy productivos para ciertos cultivos hortofrutícolas y algunas manchas de bosque galería.

La articulación de este paisaje está marcada por la presencia de dos elementos en conjunción: las sierras y los valles fluviales. Las primeras marcan límites reales y simbólicos, circunscriben y determinan la movilidad y estructuran el espacio en la comarca. Los valles fluviales articulan la movilidad en estas zonas en la mayoría de los casos y funcionan como vías de comunicación entre este espacio y los espacios externos a la propia comarca, que se encuentra bastante encerrada en sí misma. Los macizos de la Sierra de Francia delimitan la barrera Norte-Sur, y la divisoria de aguas entre las dos principales cuencas fluviales del occidente de las dos mesetas, la del Tajo y la del Duero. La Sierra de Quilamas divide la zona en dos partes según su eje noroeste-sudeste, una hacia el oriente, en la Cuenca del Alagón, que fluye hacia el sur y la otra hacia los llanos de Ciudad Rodrigo y las cuencas del Yeltes-Huebra.

Dentro de esta zona, como sucede en toda la parte sudoccidental de la Meseta Norte, la densidad de yacimientos no es muy alta, sino más bien lo contrario. Las evidencias descritas en trabajos anteriores (Maluquer de Motes, 1956; Morán Bardón, 1919, 1940, 1946) o los registros del Inventario de la Diputación de Salamanca tan solo reseñan unos pocos asentamientos dispersos y mal conocidos. Tras cuatro años de trabajos de prospección y la realización de sondeos selectivos en la zona se ha comprobado que el numero real de asentamientos es verdaderamente bajo, pero su adscripción cronológica es ahora más completa y la caracterización paleoambiental ayuda a establecer una secuencia clara de los procesos sufridos durante la Protohistoria.

De los yacimientos estudiados y prospectados en esos trabajos se eligieron, para ser sondeados, los que parecían poder contener mejor información para completar esa secuencia paleoecológica, económica y cultural. El yacimiento de El Castil de Cabras, en plena Sierra de Quilamas, presenta una morfología y evidencias materiales que indicaban un primer momento de sedentarización en la zona, antes del cual no se conoce ningún hábitat. Por el contrario, La Corona, corresponde a una morfología mejor conocida y más difundida de asentamientos estables amurallados de la segunda Edad del Hierro, de gran extensión en el 
recinto, dominando zonas más amplias de terreno. Por último, como elemento representativo de los movimientos ocurridos tras la implantación de la administración romana, la primera evidencia en el entorno parecía encontrarse en el asentamiento de La Mata del Castillo. Así, en conjunto, se puede obtener una visión de los cambios producidos por las estrategias económicas y sociales de los grupos que forman cada paisaje. Estos indicadores son, en si mismos, información muy valiosa para la estructuración de una interpretación social de las formas y motores del cambio en estos grupos.

\section{Trabajos en el Castil de Cabras}

El Castil de Cabras se encuentra ubicado a una altura de $1046 \mathrm{~m}$ en el interior del valle del Río Quilamas, en la sierra del mismo nombre, en el área oriental de la comarca de la Sierra de Francia (Est. II). $\mathrm{Su}$ inaccesibilidad y la construcción de, al menos, dos paramentos de aterrazado, han favorecido la conservación del sitio. Este asentamiento se encuentra sobre una pequeña plataforma en lo alto de una elevación que cae por el sur en una fortísima pendiente de más de 200 metros de desnivel sobre el Arroyo de Quilamas. El espacio de la plataforma cuenta con una superficie habitable inferior a los $500 \mathrm{~m}^{2}$. El saliente, que forma parte del macizo cuarcítico de la Sierra, continúa una dinámica de canchal que, en su momento, debió servir también como fuente de matera prima para el asentamiento prehistórico.

La especial ubicación del asentamiento está cuidadosamente elegida y reúne una importante cantidad de elementos que tan sólo podían darse, dentro del área interior del valle de Quilamas, en este punto exacto. Como más tarde probaremos, los recursos que sostuvieron la economía de este grupo se localizan en un espacio bastante inmediato y el pequeño territorio de explotación planificada (agricultura y pastoreo) se combina con recursos de explotación oportunista (producidos por el bosque y el monte) en un espacio de control directo muy reducido.

La primera referencia a este yacimiento se debe a los trabajos del Padre Morán en la zona de la Sierra de Francia. Después de varias obras sobre Salamanca y alguna recopilación provincial, es en su trabajo de 1946, Reseña Histórico Artística de la Provincia de Salamanca, donde aparece un comentario e incluso una fotografía de la vertiente noroccidental del Castil de Cabras (Morán, 1946: 51). Entonces ya se calificó 
como un asentamiento tipo "castro", de la Edad del Hierro. Más tarde lo recoge también Maluquer (1956: 38) en la Carta Arqueológica de España. Salamanca, repitiendo casi en su totalidad la información dada por Morán. Desde entonces tan sólo se ha vuelto a hacer referencia a este yacimiento por el descubrimiento de algunas pinturas rupestres en la zona Sudoeste del cortado, documentadas por Ramón Grande del Brío (1987: 138).

El objetivo de los sondeos se centró en dos puntos fundamentales: la definición de la zona de aterrazado exterior y la determinación de sus características (sondeo A) y la localización de niveles muestreables en las zonas interiores del poblado (sondeos $\mathrm{B}$ y C).

Del sondeo A se obtuvieron datos sobre la técnica constructiva y las características de los paramentos, pero no niveles claros de muestreo. De los sondeos B y C, sin embargo, se extrajeron numerosas muestras pertenecientes a niveles de ocupación y abandono inmediato. Los sondeos, de 2x4 metros, muestran una estratigrafía homogénea, con un solo nivel de ocupación muy marcado y una rápida cubrición en su abandono.

En el sondeo B se documentan dos muros en muy mal estado de conservación y una zona de suelo poco consolidada la cual parece más probable que fuera un área de paso o uso esporádico que una zona de actividad u ocupación. El sondeo C, sin embargo, proporcionó una clara zona de actividad de procesado y almacenaje de grano, con numerosos restos carpológicos bien conservados aún gracias a un nivel de incendio muy localizado.

En todos los casos los materiales cerámicos se mostraban muy homogéneos, todos ellos a mano, con algunas formas influenciadas ya por el mundo del sudoeste y una importante serie de vasitos de pequeño tamaño con elementos de suspensión vertical. Se trata de un conjunto de materiales en el que predomina la producción no estandarizada. Sin embargo, se pueden destacar dos elementos bien diferenciados en esta producción: las formas abiertas que evocan sistemas de ritual asociado a un consumo de alimentos colectivo y la proliferación de vasitos de pequeño tamaño, de fondo redondeado y en ocasiones con perforación vertical. Estos elementos, de carácter individual, representan en este yacimiento una importante muestra y vienen a completar una serie de hallazgos ya documentada en algunos sitios de Ávila (Fabián, 1999: 168-173), Cáceres (Martín Bravo, 1999: 88-90) o Portugal (Vilaça, 1995: 116-122) con las mismas características. Las formas abiertas, por 
otra parte, se relacionan también con la proliferación de elementos pintados provenientes del sudoeste y que están documentados en la zona desde el siglo IX a. C. en San Pelayo (Benet, 1990). Su versión más sencilla se encuentra en el registro del tránsito del Bronce Final al Hierro en esta zona salmantina-abulense asociada con regularidad a estos vasitos (Fabián, 1999: 171).

\section{Toma de muestras en El Castil de Cabras}

Todas las recogidas han seguido una misma metodología de extracción. Los sedimentos seleccionados se encuentran bien definidos en estratos cuyas características de formación son claras y componen horizontes edafológicos bien definidos. Siguiendo el procedimiento habitual de recogida de muestras se depositaron en bolsas de plástico los sedimentos directamente extraídos de los estratos en el perfil, seleccionando muestras de alrededor de 500 gr (Est. III).

Las muestras de El Castil de Cabras analizadas en el laboratorio del CSIC fueron cinco. De ellas, la primera (QCCMP1) corresponde a la unidad 53, del sondeo B, formada por un lentejón de tierra arcillosa rojiza bastante granulosa, de origen antrópico. La segunda de las muestras (QCCMP2) pertenece a la unidad 52, que es la unidad de colmatación superior inmediatamente posterior al abandono del poblado, formada por tierra muy orgánica, de color casi negro, en la que aparecen mezclados cantos rodados y restos de arcilla. Una última muestra del sondeo B (QCCMP3) proviene de la unidad 55, que forma la base sobre la que asienta la UE 53. Se trata de un sedimento muy orgánico y bien definido entre M1B y la línea de piedras que parece estar formando un momento de ocupación del asentamiento anterior al de la unidad 53 que es, sin embargo, perfectamente homogéneo en sus materiales con las demás unidades.

Las siguientes dos muestras se tomaron en los niveles de abandono y uso del sondeo C. La primera (QCCMP4), corresponde con este nivel de abandono inmediato al nivel de habitación del área de actividad. Este sedimento conserva una gran horizontalidad en la sedimentación e importante potencia. Se trata de elementos con un alto contenido orgánico, formado por arenas arcillosas. Incluye piedras de mediano y pequeño tamaño pero también lajas más grandes de cuarcita. La última de las muestras se tomó en la unidad correspondiente al área de proce- 
sado de cereal (QCCMP5). Conserva la horizontalidad en su formación, mostrando un importante nivel de incendio, muy oscuro y con abundantes carbones en toda el área de ocupación, pero muy localizado. La base se compone de arenas de grano medio bastante arcillosas. $\mathrm{Su}$ potencia es escasa pero se encuentra muy compactado y con elementos in situ. Entre los restos de contenedores cerámicos destruidos se recuperaron semillas de Triticum aestivium y Vitis vinifera carbonizadas.

\section{Resultados obtenidos en El Castil de Cabras}

Del sondeo B de este yacimiento proceden tres muestras palinológicas ubicadas en las unidades estratigráficas UE 52, 53 y 55. Sólo la muestra procedente de la UE 53 resultó polínicamente estéril debido a la naturaleza fuertemente arcillosa de su sedimento. Las otras dos sí resultaron positivas gracias a su elevado contenido orgánico, a pesar de su estructura básicamente arcillosa. Del sondeo C, por su parte, se recogieron otras dos muestras polínicas de un sedimento de arenas arcillosas altamente orgánico, procedentes de las unidades 101 y 102 (Est. IV).

El porcentaje de polen arbóreo, en las 4 muestras que resultaron fértiles polínicamente hablando, no es demasiado alto (ca. 35-42\%), lo que da cuenta de un paisaje forestal bien desarrollado pero más o menos abierto, donde las especies preponderantes serían los Quercus caducifolios (roble, quejigo), y en menor medida el alcornoque (Quercus suber) o la encina (Quercus perennifolios). El bosque ripario, en cambio, aparece bien representado tanto por el aliso (Alnus) como el fresno (Fraxi$n u s$ ) o el sauce (Salix), indicando posiblemente una buena conservación de tales ecosistemas. Otros elementos arbóreos menores serían el enebro (Juniperus type) que formaría parte de la clímax del encinar; o los pinares montanos (Pinus sylvestris type), cuyos porcentajes inferiores al $2 \%$ indican su carácter alóctono. Cabe reseñarse, igualmente, la presencia en las muestras de las UE 52, 55 y 102 del avellano (Corylus), con ca. $3 \%$, lo que indicaría su presencia en el seno de la ripisilva con toda probabilidad. Entre la flora arbórea, una constatación importante es la presencia en todas las muestras de polen de castaño (Castanea) con porcentajes que oscilan entre el 3 y el 6\%, lo que vendría a refrendar el carácter autóctono de este taxón durante la Edad del Hierro en la Sierra de Francia. 
La flora arbustiva supone el 25-30\% del polen total, siendo Cistus ladanifer (jara pringosa), Erica (brezo) y Arbutus (madroño) los palinomorfos mejor representados, que corresponderían a facies degradativas del bosque climácico. El carácter térmico y subhúmedo del clima en este periodo, y para la zona de estudio, vendría refrendado no sólo por la presencia de madroño, sino también de durillo (Viburnum) y cornicabra (Pistacia terebinthus); el primero formaría parte del cortejo florístico de la aliseda, mientras que la segunda ocuparía con toda probabilidad las ubicaciones más expuestas y de vocación rupestre del territorio, allí donde la humedad edáfica favorecería su instalación en contra de la encina o el enebro, que preferirían zonas más soleadas y con mayor xericidad estival.

La flora herbácea constituye ca. 30-40\% del polen total, reflejando ese carácter abierto del medio antes expuesto. Entre ésta, destacan los porcentajes de gramíneas (15-20\%), y en menor medida de Cruciferae, Umbelliferae, Leguminosae, Liliaceae, etc. Los taxones de ámbitos nitrófilos, aquellos que prosperarían en las zonas más antropizadas o ruderalizadas, están representados por Cichorioideae, Cardueae, Chenopodiaceae/Amarantahceae, Aster type, Plantago sp. y Rumex sp. El porcentaje de flora nitrófila, sin embargo, no es demasiado alto (ca. $10 \%$ en su conjunto).

Sin duda alguna, un aspecto fundamental de la investigación palinológica en este yacimiento ha sido la identificación de polen de cereal, con porcentajes que oscilan entre el 3-4\% para las muestras de las UEs 52 y 55 , y de hasta un $11 \%$ en la de la UE 102. En la muestra de la UE 101 , sin embargo, no se encontró. Estos datos vendrían a corroborar el cultivo del cereal en las zonas aledañas al asentamiento, en un radio no superior a 100 m, ya sea en las vaguadas más húmedas de los cauces fluviales locales e incluso en zonas aterrazadas. Los porcentajes observados de cereal en la UE 102 son demasiado altos, lo que podría corroborar la incorporación de polen de cereal junto a las espigas para su molienda, es decir serían un aporte de carácter antrópico (indirecto) que no natural (directo).

La flora hidro-higrófita viene representada por un amplio dosel de pteridófilos (Filicales monoletes y triletes), donde cabe destacarse Polypodium vulgare type, un helecho que refrendaría la benignidad climática, al menos la humedad ambiental, y la vocación rupestre de la zona de estudio. El Pteridium aquilinum (helecho águila) alcanza valores de hasta el $30 \%$ con respecto a la suma base polínica, siendo un buen ejem- 
plo de la abundancia de zonas aclaradas donde prosperaría este helecho. Las Cyperaceae, con un 10-15\%, refrendarían la buena conservación del bosque ripario antes expuesta y la humedad edáfica reinante.

Aunque en todas las muestras aparecen microcarbones, siempre en porcentajes relativamente bajos, es en la muestra de la UE 102 donde su concentración es muy alta, del orden de 1500 x $10^{3}$ fragmentos $/ \mathrm{cm}^{3}$, lo que unido a la abundancia de esporas fúngicas de especies carbonícolas (Chaetomium sp. muy especialmente) en esta misma muestra, corroborarían la existencia de un nivel de incendio, posiblemente de carácter local, en esta unidad estratigráfica.

\section{Trabajos en la Corona}

El yacimiento de La Corona, se sitúa en uno de los extremos occidentales de la Sierra de Quilamas, en su vertiente noroccidental. El yacimiento se situa en la cima de un monte destacado en el entorno cuya altura total es de $1288 \mathrm{~m}$, delimitando su perímetro una extensión aproximada de 4,5 ha (Est. VII).

Rodeado por una muralla de una potencia muy considerable, fue definido como "castro céltico" por Morán (1946: 39) y más tarde por Maluquer (1956: 54), tras lo que quedó en un olvido del que apenas había salido. En la actualidad, con los trabajos de prospección desarrollados desde los años ochenta, se volvió a intentar documentar los elementos arqueológicos de la zona, pero al definirse las estructuras de la Sierra de Quilamas (Pico Cervero, Los Molinos, La Cruz de la Cabeza, y principalmente El Castillo Viejo de Valero) como pertenecientes a época histórica (Santonja et al., 1987), este yacimiento fue asimilado a este proceso más moderno.

Las prospecciones en la Sierra de Francia no revelaron ningún material en la primera visita a este yacimiento, pero el estudio atento de las estructuras visibles, la fotointerpretación y posteriores revisiones del sitio llevaron a pensar en la posible adscripción prehistórica del lugar. En él aparecen elementos estructurales, como la construcción de la entrada en codo, situada en el sector Sudeste, así como los dos únicos restos encontrados en superficie, dos fragmentos de molino barquiforme, uno sobre esquisto y el otro sobre granito, que apuntaban hacia su poblamiento durante la Edad del Hierro. 
La muralla recorre el recinto en su lado más accesible, el este, y se va estrechando y perdiendo potencia según se va cerrando sobre el cortado de su parte más occidental. Su espesor parece ser muy variable y su trazado muy irregular, pero no ha sido posible documentar más que en su parte distal en la zona norte (Sondeo F) donde ya tiene muy poco grosor. Calculamos que podría alcanzar unos 5 a 6 metros de ancho en muchos lugares del lienzo principal, a juzgar por la traza del aterrazado y el grosor de los parapetos que dan forma al pasillo de la entrada.

La gran extensión del espacio delimitado por el muro hacia muy difícil la elección de un lugar que asegurara la consecución de una secuencia estratigráfica y zonas de muestreo fiables. Se realizaron seis sondeos, cinco en el interior del recinto a diferentes alturas y uno en la zona más septentrional de la muralla. Los cinco interiores, A, B, C, D y $\mathrm{E}$, de $2 \times 4$ metros, produjeron una importante cantidad de material de arrastre propio de la Segunda Edad del Hierro y algún fragmento aislado probablemente calcolítico, pero ningún elemento de referencia sobre el hábitat. El sondeo F, por el contrario, permitió descubrir el basamento de la muralla y una importante bolsada de materiales sujeta por esta estructura y sellada por su derrumbe. De este sondeo, de 2x10 metros, formado por seis unidades estratigráficas, tenemos una importante muestra de material cerámico y fauna, además de la palinológica.

\section{Toma de muestras en La Corona}

En este caso todas las muestras recuperadas fueron tomadas en los niveles que formaban el contexto estratigráfico relacionado con la estructura de la muralla, en el sondeo F. Las muestras recuperadas fueron cuatro.

La primera de ellas (LCMP1) corresponde a la unidad 202, que es producto de la formación de ladera correspondiente a la fase de abandono del yacimiento. La formación del depósito representa una bolsada de material sellado bajo el derrumbe interno de la muralla, compuesto por un sedimento más arenoso, con gran cantidad de material cerámico, fauna y elementos líticos. La formación de este depósito parece bastante homogénea, y los elementos materiales poco rodados parecen indicar una importante cercanía del foco emisor. La segunda de las muestras (LCMP2), que corresponde a la unidad 201, parece pertenecer al momento de abandono del yacimiento. Se trata de un sedimento más rojizo, 
fruto de la erosión de las calizas, compactado, frenado por el derrumbe de la muralla. Se desarrolla inmediatamente por debajo de unidad estratigráfica que compone el estrato de superficie, denominada UE 200, desde el perfil sur al derrumbe de la muralla, y que contiene todavía algún material bastante entero. La tercera muestra (LCMP3) proviene de la unidad 204, formado por el sedimento del preparado de la muralla que es bastante abundante en su base. Se compone de arenas arcillosas claramente seleccionadas para recibir los grandes bloques de caliza que forman la base de la muralla. Por último, la siguiente muestra proveniente de la propia base de fundación de la muralla, en la unidad 205 (LCMP4).

\section{Resultados obtenidos en La Corona.}

De este yacimiento se estudiaron palinológicamente 4 muestras, procedentes de las UEs 201, 202, 204 y 205, todas ellas del sondeo F. Esas fueron por completo polínicamente fértiles, aunque aquélla de la UE 205 demostró una concentración polínica relativamente inferior a las otras tres debido a su componente arcilloso (Est. V).

El porcentaje de polen arbóreo en las 4 muestras estudiadas es relativamente bajo y oscila entre el $20-27 \%$, lo que reflejarían un paisaje bastante abierto, no demasiado forestado. La especie dominante en este paisaje sería el roble melojo (Quercus caducifolios), que posiblemente daría lugar a las formaciones forestales entorno al propio yacimiento e incluso poblaría toda la sierra de Quilamas en este periodo. Con porcentajes inferiores al 5\% aparecen Quercus perennifolios así como Quercus suber (alcornoque), reflejando que tanto encinares como alcornocales tendrían un carácter regional que no local en nuestra zona de estudio. Lo mismo puede afirmarse de los pinares montanos (Pinus sylvestris type), cuyo porcentaje del $0,7-1,2 \%$ obedece a su carácter alóctono. El bosque ripario apenas aparece representado en los espectros polínicos, siendo el aliso (Alnus) y el fresno (Fraxinus) los únicos palinomorfos representados, con valores en todo caso inferiores al $4 \%$, lo que denotaría posiblemente su lejanía respecto al yacimiento o su deforestación caso de encontrarse en el entorno. Tanto el avellano (Corylus), el abedul (Betula) como el castaño (Castanea), aparecen representados en las 4 muestras con porcentajes en todo caso cercanos al 2-3\%, lo que reflejaría su carácter autóctono en la zona de estudio, posiblemente en el seno de bosques riparios donde encontrarían refugio. 
La flora arbustiva representa el 15-23\% del polen total, siendo Cistus type (jarales), y Erica arborea type (brezo) los palinomorfos dominantes, que formarían parte del sustrato arbustivo que poblarían el subvuelo del melojar en las zonas más degradadas y posiblemente aclaradas. Cabe destacar que la jara pringosa (Cistus ladanifer) apenas representa el $0,7 \%$, lo que implicaría una dominancia de otro tipo de jarales posiblemente de carácter más húmedo.

Por su parte, la flora herbácea se constituye en el elemento fundamental que define la fisonomía del paisaje entorno a este yacimiento para el periodo cronológico de estudio, ya que ésta representa casi el 35$-50 \%$ del polen total. Tal desarrollo de la flora herbácea, fundamentalmente de los pastizales de gramíneas, nos haría pensar en un paisaje muy abierto, como antes se comentó, con abundancia de zonas aclaradas en el seno de las formaciones forestales, donde medrarían especies arbustivas de las etapas degradativas del melojar pero, sobre todo, formaciones graminoides muy abundantes y bien extendidas localmente. Además de Gramineae, entre la flora herbácea se han identificado Liliaceae, Cruciferae, Leguminosae, Umbelliferae, etc. Entre este elenco florístico cabe destacarse también la abundancia de taxones de carácter nitrófilo (Cichorioideae, Cardueae, Aster type) que implicarían la antropización del medio, al menos localmente.

A diferencia de lo que ocurría en El Castil de Cabras, en las muestras analizadas en La Corona no ha podido identificarse polen de cereal, aunque el emplazamiento en alto del yacimiento podría haberse constituido en un impedimento para la llegada del polen hasta los sedimentos estudiados, caso de haber existido en estos momentos algún tipo de cultivo cerealístico. Sea como fuere, la palinología no puede constatar actividades agrícolas que impliquen cerealicultura.

La flora hidro-higrófita muestra un clima relativamente húmedo, ya que abundan los Filicales tanto monoletes como triletes, así como Cyperaceae. El helecho águila (Pteridium aquilinum) alcanza porcentajes superiores al 35\%, demostrando el carácter sumamente abierto del medio, donde este pteridófito prosperaría abundantemente, acompañando a los pastizales graminoides antes descritos.

Entre los microfósiles no polínicos identificados, aparecen algunos indicativos de procesos de incendio, tanto de carácter local como regional, caso de Chaetomium sp. y Coniochaeta cf. ligniaria, pero sus porcentajes son muy bajos y dentro del cortejo palinológico no existen elementos paralelos de tales fenómenos. 
En cambio, un hecho fundamental que acontece en este yacimiento es la identificación de microfósiles no polínicos que por su carácter coprófilo son indicativos da la presencia de ganado en el entorno. Tal es el caso de los types 55 y 112 . Ambos aparecen representados en las cuatro muestras estudiadas, con porcentajes cercanos al 6-8\%, excepto en la muestra de la UE 202 donde su porcentaje conjunto supera el $23 \%$. Estos datos vendrían corroborados por otros palinomorfos tales como Plantago lanceolata type, Chenopodiaceae/Amaranthaceae y Urtica dioica type, cuya presencia conjunta se ha interpretado igualmente como resultado de actividades agropastoriles.

En resumen, los datos paleopalinológicos parecen demostrar que el paisaje entorno al yacimiento de La Corona tuvo un carácter sumamente abierto, donde el melojar era el bosque predominante y donde en sus numerosas zonas aclaradas abundaban pastizales de gramíneas. Cabe pensar que la fisonomía de este paisaje tuvo un origen fundamentalmente antrópico, donde la presencia de ganado en el medio tuvo que ser determinante.

\section{Trabajos en la Mata del Castillo.}

El yacimiento conocido como La Mata del Castillo, se ubica en la meseta alargada que forma el alto de un cerro, en la vertiente occidental de la sierra de Quilamas, cuya cota máxima es de 1149 m (Est. VIII). Este alto, alargado en dirección noroeste-sudeste, mide aproximadamente unos $350 \mathrm{~m}$ de longitud por entre 50 y 100 metros en anchura.

De fácil acceso desde la vertiente Norte se asoma a un importante cortado hacia el sur, sobre las vistas de la Peña de Francia, con afloramientos de pizarras y esquistos de gran tamaño. En la superficie del yacimiento se pueden apreciar aterrazamientos artificiales y elementos excavados en la roca que parece que sirvieran para situar estructuras sobre el cortado sur. Existen al menos tres de estos elementos de cimentación rupestre claramente visibles en la actualidad.

De todos los lugares que hemos citado éste es por el que más interés demostró César Morán, haciendo referencia al material encontrado y a la posible adscripción de éste (Morán, 1946: 23). Como en los casos anteriores, la Carta Arqueológica de Salamanca de Maluquer (1956: 65 ) hacía referencia en la misma proporción a este sitio, que además de tener material en superficie era bastante más accesible que los otros. 
Tras estas noticias, vuelve a producirse un vacío en la investigación hasta las prospecciones de los años ochenta. Ha sido adscrito a varios periodos históricos, desde el Calcolítico a la Edad Media, pero sin elementos arqueológicos de juicio que resultaran definitivos.

Las prospecciones realizadas anteriormente habían recuperado gran cantidad de cerámica a mano y torno, bastante rodada. En los trabajos desarrollados recientemente por el equipo del CSIC (Sánchez-Palencia, Ruiz del Árbol, y López Jiménez, 2000, 2001) se pudieron recuperar numerosos elementos de cerámica a mano, a torno, algún un posible resto de construcción de época romana, como restos de ladrillo, y una laja de pizarra esquistosa con orificios, preparada para ser fijada a la techumbre, así como algunos fragmentos de escoria de $\mathrm{Fe}$.

Entonces ya parecían estar claramente diferenciadas dos áreas. Una de ellas corresponde a la meseta superior, con gran cantidad de cerámica tosca a mano y a torno, sin decoración, principalmente visible en su ladera suroccidental y alrededor de una serie de cimientos excavados en los afloramientos de roca. La otra área se sitúa sobre la meseta más amplia y algo más baja que se desarrolla hasta el límite norte, donde se recuperaron elementos que parecían cerámicas refractarias de tipo romano, un posible fragmento de ladrillo y escorias.

Los sondeos se centraron en este caso, debido a la gran extensión de la plataforma del asentamiento, en la parte más alta del mismo, donde la frecuencia y variedad de los hallazgos de superficie parecía indicar una mayor potencia arqueológica. Se realizaros dos sondeos de forma casi paralela. El primero de ellos (sondeo A), de 2x4 rápidamente reveló una estructura de enlosado de pizarra, bastante bien conservado, que se continuaba hacia el este. En ese punto se planteo el siguiente sondeo (B), de $2 \times 5$, que completaba la imagen de esta estructura que parecía formar parte de un exterior.

El registro material, debido a la escasa potencia del sedimento, fue muy poco significativo, pero la conservación de las capas de preparado de la estructura permitieron tomar muestras de estratos sellados, y los restos orgánicos hallados completan la información paleoambiental con datos de radiocarbono sobre la fundación y abandono de la estructura. 


\section{Toma de muestras en La Mata del Castillo}

En este caso las muestras recogidas corresponden a los niveles de fundación de los enlosados documentados en los sondeos A y B. Las muestras recuperadas fueron tan solo dos.

La primera de ellas (MCMP1) fue extraída de la unidad 01 en el sondeo A, compuesto por un nivel arenoso amarillento, rodeado por la estructura formada por M1A, formando un preparado en el que va incluida cerámica mas entera y sin el rodamiento de la fase anterior (UE00). La segunda (MCMP2) pertenece a la unidad 53, que es la base del enlosado en el sondeo B y que parece comportarse como UE 01, proporcionando también algunos materiales incluidos en el preparado. Se desarrolla tan sólo por debajo de UE 52 en el área delimitada por el enlosado. Como en el caso de UE 01 es de color amarillento y textura arenosa.

\section{Resultados obtenidos en La Mata del Castillo.}

En este yacimiento únicamente se estudiaron dos muestras, una procedente de la UE 01 (sondeo A) y la otra de la UE 53 (sondeo B). El estudio de únicamente dos muestras, procedentes además de dos ambientes sedimentarios distintos, puede limitar en cierta manera nuestra interpretación paleoecológica, pues muchos son los factores de índole tafonómico que podrían haber intervenido sobre ellas. No obstante, los resultados palinológicos de su estudio son muy similares, lo que nos lleva a pensar en cierta contemporaneidad cronológica así como en la ausencia de alteraciones postdeposicionales importantes (Est. VI).

La flora arbórea apenas representa el 7-13\%, dando cuenta de una paisaje muy deforestado, sumamente abierto, donde el roble melojo (Quercus caducifolios) sería la especie predominante, con una presencia testimonial de encina, enebro y alcornoque. El pino montano sigue apareciendo con carácter alóctono y no se detecta presencia alguna de elementos arbóreos propios del bosque ripario, lo que nos lleva a pensar en su desaparición total en el entorno de este yacimiento.

Es muy reseñable la identificación de polen de Olea europaea con un 4-7\%, lo que nos haría pensar posiblemente en el cultivo del olivo, aunque cabe también la posibilidad de la presencia natural de su forma silvestre o acebuche, cuya presencia ha venido demostrada ya en perio- 
dos cronológicos anteriores en otros estudios palinológicos llevados a cabo en las sierras de Francia o Béjar, e incluso en el occidente abulense.

La flora arbustiva tampoco aparece bien representada, con apenas el 5-7\%, siendo Labiatae, Cistus ladanifer y Cistus type los palinomorfos presentes. Estos datos darían cuenta del alto grado de deforestación del medio, que habría actuado incluso sobre las formaciones de matorrales.

Entre la flora herbácea el predominio corresponde a los palinomorfos de marcado carácter antrópico, sobre todo a aquellos de carácter nitrófilo, caso de Cardueae, Cichoriodeae, Rumex sp., Plantago sp., etc, que en conjunto alcanzan casi el $30 \%$ del total. Entre el resto de flora herbácea dominan las gramíneas y en menor medida Leguminosae y Cruciferae.

En ambas muestras se ha identificado polen de cereal, con un $0,7 \%$ en la de la UE 01 y un 2,3\% en la de la UE 53. Al menos para la de la UE 53 podría afirmarse el cultivo local de cereal en el entorno del yacimiento.

Es importante reseñar, entre los microfósiles no polínicos, la identificación de clamidosporas de Glomus cf. fasciculatum, en porcentajes del 11-18\%, cuya presencia en las muestras estudiadas cabe interpretarse como consecuencia de la existencia de procesos erosivos notables in situ. De la misma manera, amerosporas de hongos carbonícolas tales como Chaetomium sp. y Coniochaeta cf. ligniaria, aparecen con porcentajes superiores al $15 \%$ respecto a la suma base polínica, lo que implicaría la ocurrencia de fenómenos que implicarían la presencia o utilización del fuego, tanto a nivel local como regional.

\section{Conclusiones en torno a la reconstrucción del paisaje protohistórico de la comarca de la Sierra de Francia.}

El estudio realizado en esta zona concreta de la Sierra de Francia muestra una importante evidencia sobre la formación y transformación de los paisajes antiguos en un periodo largo de tiempo. Sólo desde la observación detallada de estos "tiempos largos" es posible reconocer con claridad sistemas sociales en proceso de transformación que representan formas muy diferentes de construcción del paisaje. En este caso los trabajos en la Comarca de la Sierra de Francia marcan dos transi- 
ciones radicales en las formas de vida de los grupos que la poblaron y una secuencia de ocupación protohistórica suficiente para comenzar a comprender cual era el carácter y la formación de estas estructuras sociales y sus motores de cambio.

La primera gran transformación se produce en el tránsito de una economía móvil a los primeros procesos de sedentarización, que en esta zona no se documentan hasta los últimos momentos del Bronce Final. A partir de este momento se produce un proceso de paulatina apropiación del espacio y proyección del grupo sobre el territorio de explotación que se resuelve, algunos siglos más tarde, entrando en la Edad del Hierro, en una total sedentarización y fijación al suelo. En este proceso, la interacción de estos grupos con un entorno comarcal o regional toma un papel primordial en la activación de mecanismos sociales y en la adopción de estrategias para la resolución de los conflictos intragrupales. El siguiente gran cambio en la zona viene directamente vinculado a una presencia exógena que fuerza una rearticulación que rompe violentamente con el concepto y formación del paisaje prerromano. Se trata, durante el siglo I a. C., de la imposición de los intereses romanos en la zona y la rearticulación del poblamiento, las estructuras sociales, de producción y las formas de relación social.

La secuencia del poblamiento y de los modelos de ocupación de esta zona representa un claro ejemplo de estructuración del territorio en el que se pueden observar los cambios más significativos producidos por el desarrollo de diferentes estrategias sociales que generan paisajes muy diversos. Los grupos del Castil de Cabras conciben todavía el paisaje como un marco flexible aunque bien delimitado, cuyas únicas referencias de fijación son las más directamente asociadas a la explotación del espacio más inmediato. Para las sociedades que poblaron La Corona ese paisaje se ha convertido ya en una proyección del propio yacimiento, visible y visualizador de un entorno articulado por su presencia, con un área de explotación bien estructurada y la necesidad de organizar de forma más firme ciertos sistemas de relaciones intergrupales. Con la ruptura del mundo romano la estructura del paisaje se transforma nuevamente $\mathrm{y}$, tras un periodo de transición y acoplamiento, seguramente muy conflictivo en lo social, se produce la instrumentalización económica del paisaje y su consecuente transformación.

En todo este proceso la imagen de una forma de organización socioeconómica se ha ido proyectando sobre el paisaje. La creciente deforestación y la transformación del medio se hacen cada vez más 
patentes. El ambiente asociado al Castil de Cabras es propio de la búsqueda de los recursos más amplios y de una mínima transformación del medio en una zona resguardada, rocosa, con varios tipos de formaciones vegetales en un pequeño espacio en torno al asentamiento. En el caso de La Corona el paisaje a cambiado, el bosque ha retrocedido alrededor del poblado y los arbustos sufren la presencia de los animales que pastan y producen una vegetación de bosque abierto sin apenas formación arbustiva. La importante presencia de esta cabaña ganadera, corroborada por los análisis palinológicos y faunísticos, también tiene una relevante incidencia en el interior del recinto por lo que posiblemente estos se guardaran, como tantas veces se ha planteado, en cercados en el interior del castro. Es posible, incluso, que se produjeran algunas quemas de zonas forestales para facilitar la proliferación de pastos, pero su incidencia parece ser muy escasa en el registro general. La verdadera transformación del paisaje, como se viene argumentando hasta ahora, se produce con la explotación romana y tiene un claro reflejo en el registro medioambiental. El bosque y sotobosque se han retirado de forma muy drástica y se potencian las zonas de pastos y cereales, con constancia de ciertos incendios recurrentes que pueden estar hablándonos de una política de quema y roza en las zonas de las vegas y terrazas de los alrededores del yacimiento. Las plantas herbáceas documentadas vienen a apoyar esta fuerte antropización del entorno con una presencia muy alta de ejemplares directamente vinculados a estos procesos. Esta fase corresponde ya a una forma de explotación del territorio de tipo romano, pese a que el material cerámico hasta ahora es parco en tipos claramente relacionados con esta presencia. Parece evidente en la zona que las formas de articulación y explotación del territorio llegaron antes a esta zona que los propios materiales tenidos como "fósil guía" de la presencia romana. En cualquier caso estas evidencias son mucho más completas y definitivas a la hora de interpretar la estructura organizativa de estos grupos ya que derivan directamente del la propia configuración social.

Esta transformación de los paisajes de la Comarca de la Sierra de Francia, que las fechas radiocarbónicas datan en la primera mitad del siglo I a. C. (López Jiménez, 2004), llega a su culmen con la implantación de las explotaciones mineras y los asentamientos estables romanos relacionados con estas, a partir de mediados del siglo I d. C. en lugares como la Fuente de la Mora, o los ríos Francia, Pinalejo o Tenebrilla (Ruiz del Árbol y Sánchez-Palencia, 1999). 


\section{BIBLIOGRAFIA CITADA}

Benet, N., 1990. "Un vaso pintado y tres dataciones de C14 procedentes del Cerro de San Pelayo (Martinamor, Salamanca)". Nvmantia 3: 77-94.

FABIÁn, F., 1999. "La transición del Bronce Final al Hierro en el Sur de la Meseta Norte.

Nuevos datos para la sistematización”. Trabajos de Prehistoria 56 (2): 161-180.

GRANDE DEL BRío, R. 1987. La pintura rupestre esquemática en el Centro-Oeste de

España (Salamanca y Zamora). Salamanca. Ed. Diputación provincial de Salamanca.

LÓPEZ JimÉNEZ, O. 2004. Dataciones radiocarbónicas en la Protohistoria del sudoeste de la Meseta Norte. Consideraciones para un trabajo por hacer. Trabajos de Prehistoria 60 (2): 131-142.

Maluquer de Motes, J. 1956. Carta Arqueológica de España. Salamanca. Salamanca. Ed. JSEA.

Martín Bravo, A. M. 1999. Los Orígenes de Lusitania. Madrid. Ed. R. A. H.

MorÁn BARDón, C. 1919. Investigaciones acerca de Arqueología y Prehistoria de la región salmantina. Salamanca.

-. 1940. Mapa Histórico de la Provincia de Salamanca. Universidad de Salamanca. Salamanca.

—. 1946. "Reseña Histórico Artística de la Provincia de Salamanca”. Acta Salmanticenia 2.

RuIz del ARbol, M., y F. J. SÁNChEZ-PALENCIA. 1999. "La minería aurífera romana en el Noreste de Lusitania: Las Cavenes del Cabaco, Salamanca”. Archivo Español de Arqueología 72: 119-139.

Sánchez-Palencia, F. J., M. Ruiz del Arbol, y O. López Jiménez. 2000. Zona Arqueológica de Las Cavenes de El Cabaco (Salamanca) IV. Sondeos de prospección y excavaciones en la zona minera y en los yacimientos y estructuras asociadas. Memoria inédita depositada en la Delegación de la Junta de Castilla y León de Salamanca en 2000.

-. 2001. Zona Arqueológica de Las Cavenes de El Cabaco (Salamanca) V. Actuaciones en la zona arqueológica y excavaciones en la Sierra de las Quilamas. Memoria inédita depositada en la Delegación de la Junta de Castilla y León de Salamanca en 2001.

Santonja, M., J. Cerrillo, F. Fabián, A. Fernández, y M. Morales. 1987. "El Castillo Viejo de Valero (Salamanca): análisis de sus características y su cronología". Zephyrus XXXIX-XL: 365-374.

VILAÇA, R. 1995. Aspectos do povoamento na Beira Interior (Centro e Sul) nos finais da Idade do Bronze. Trabalhos de Arqueologia. Monografía 9. 


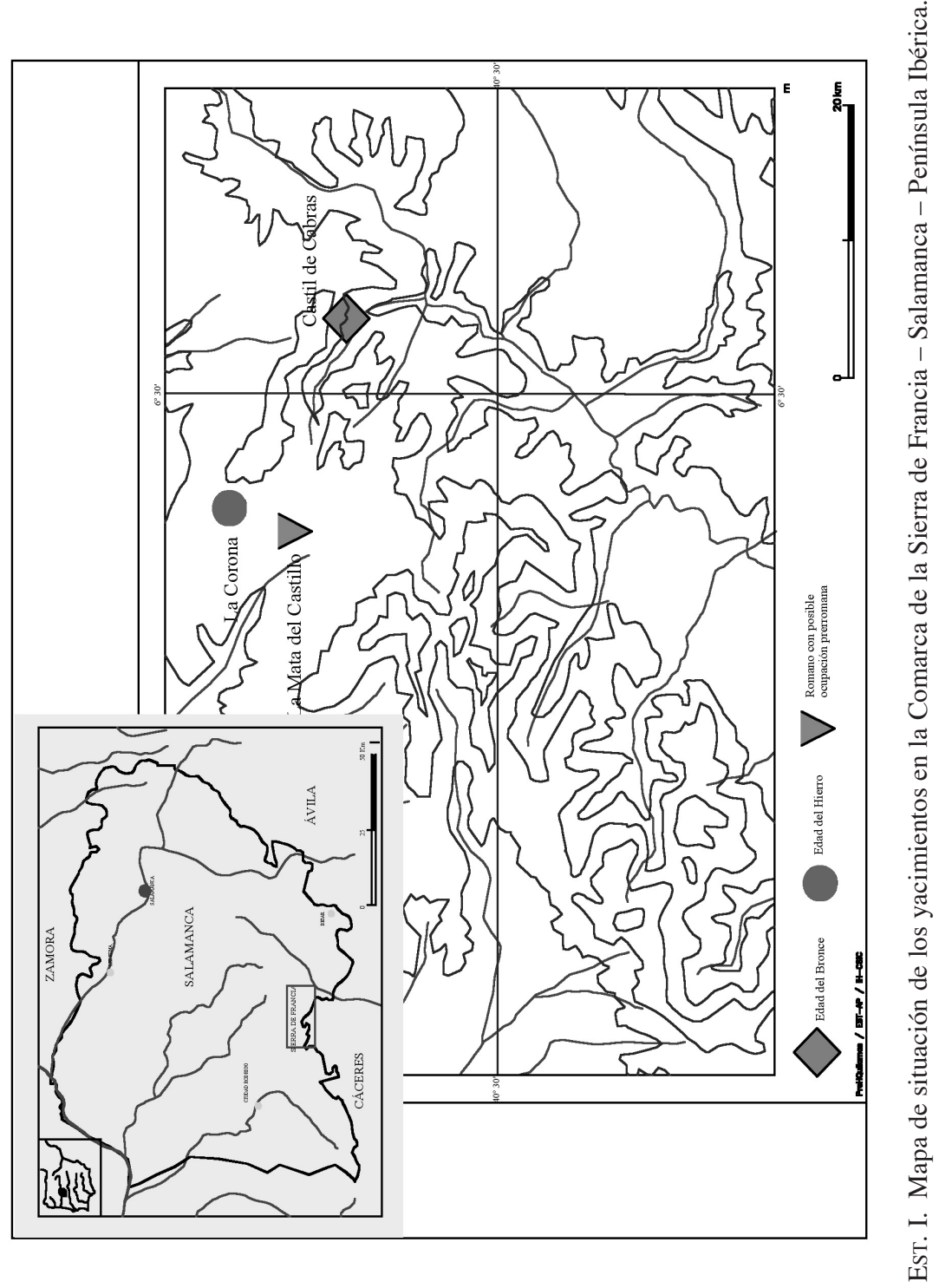




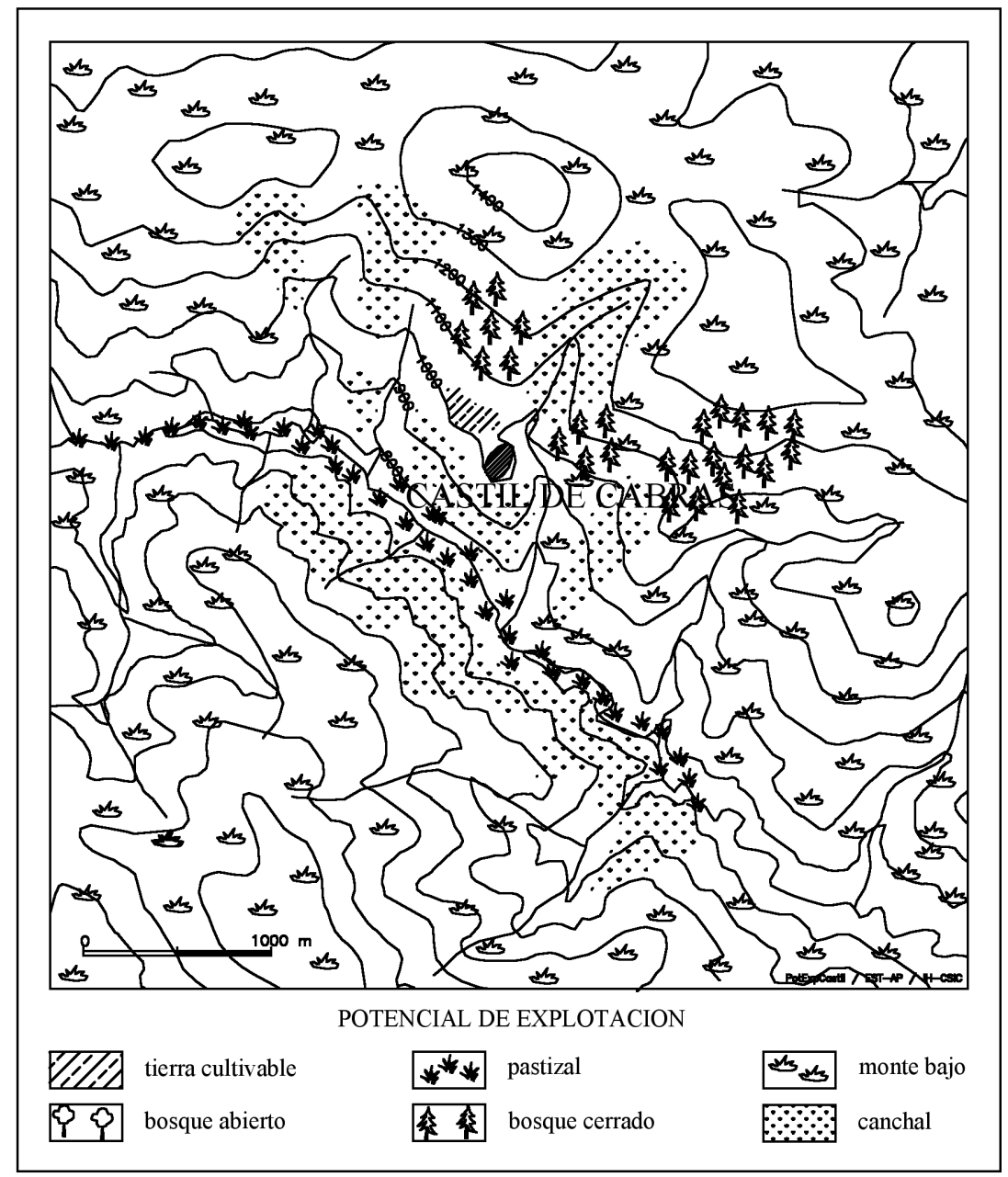

EST. II. Situación del Castil de Cabras en su entorno y características del área inmediata de captación de recursos. 


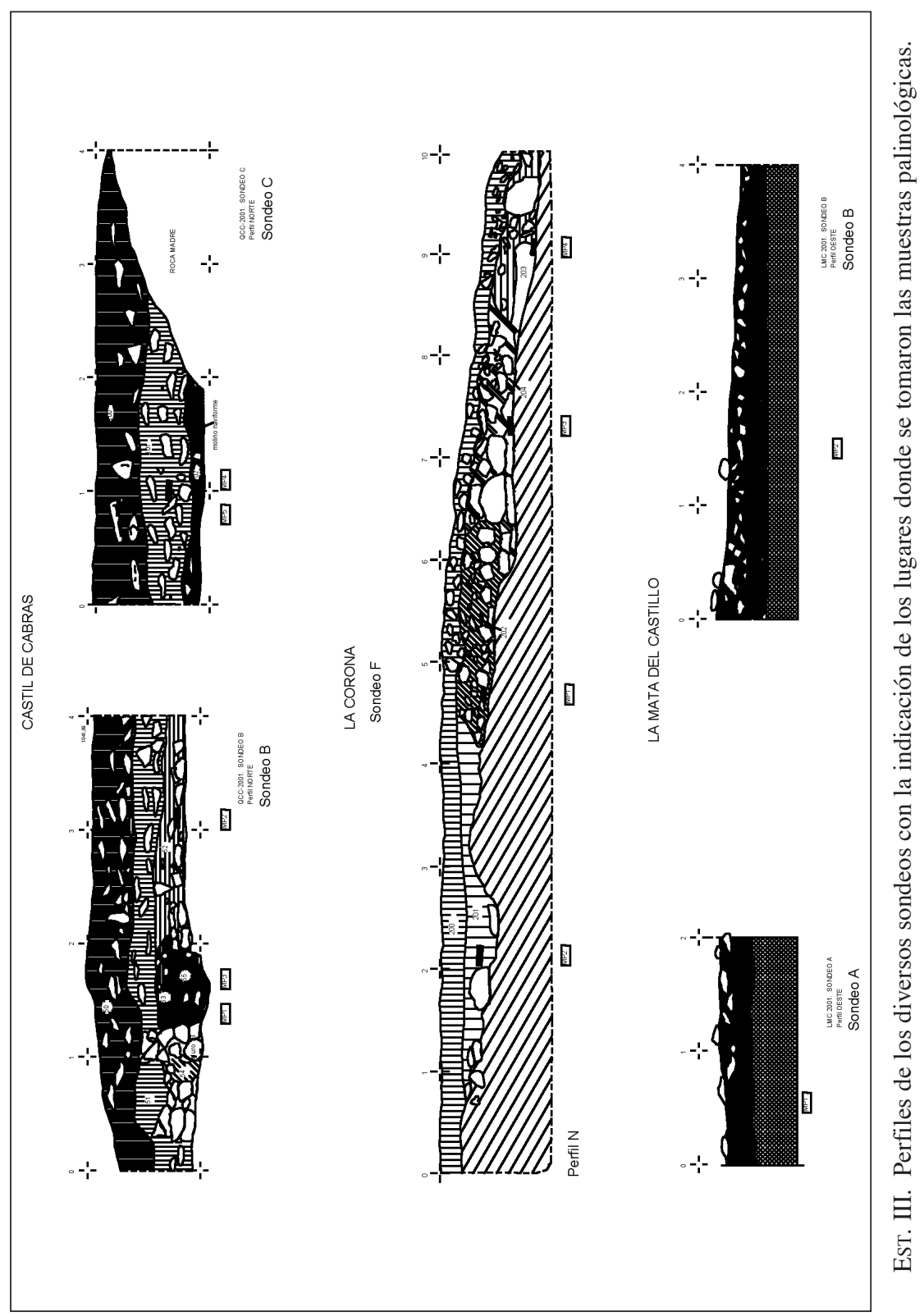




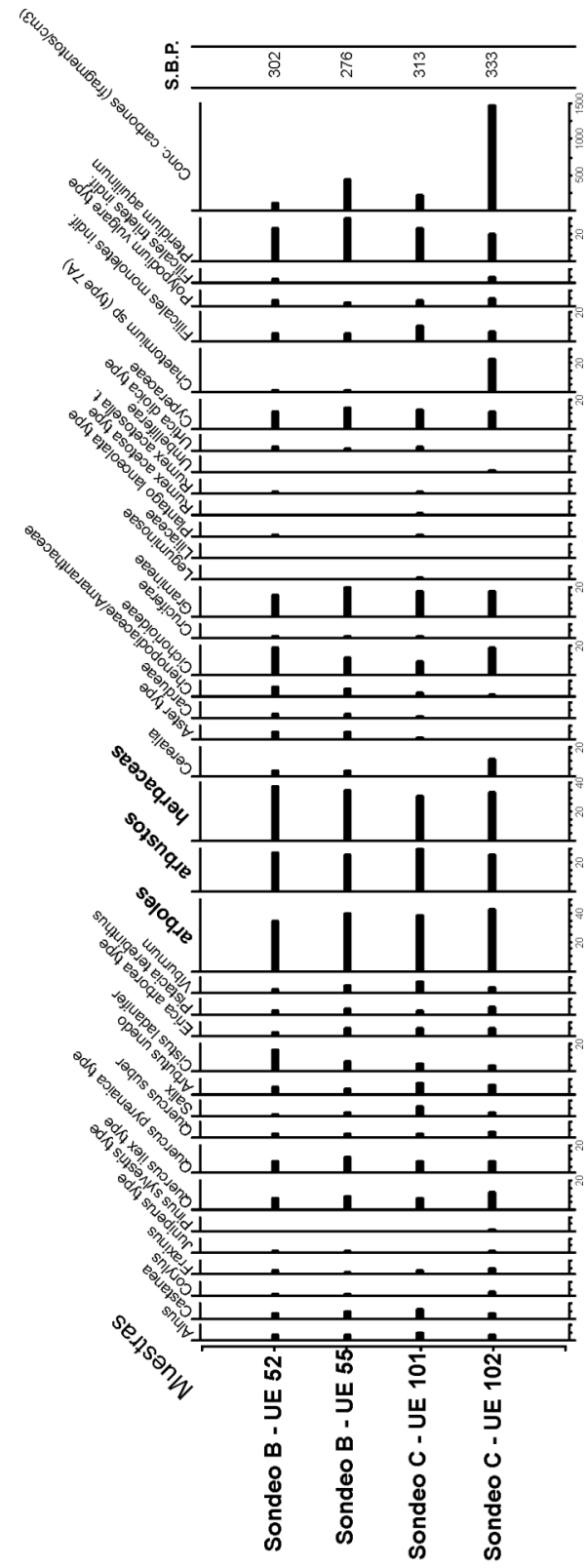

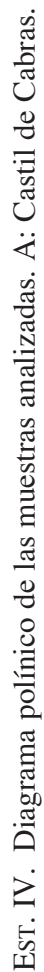




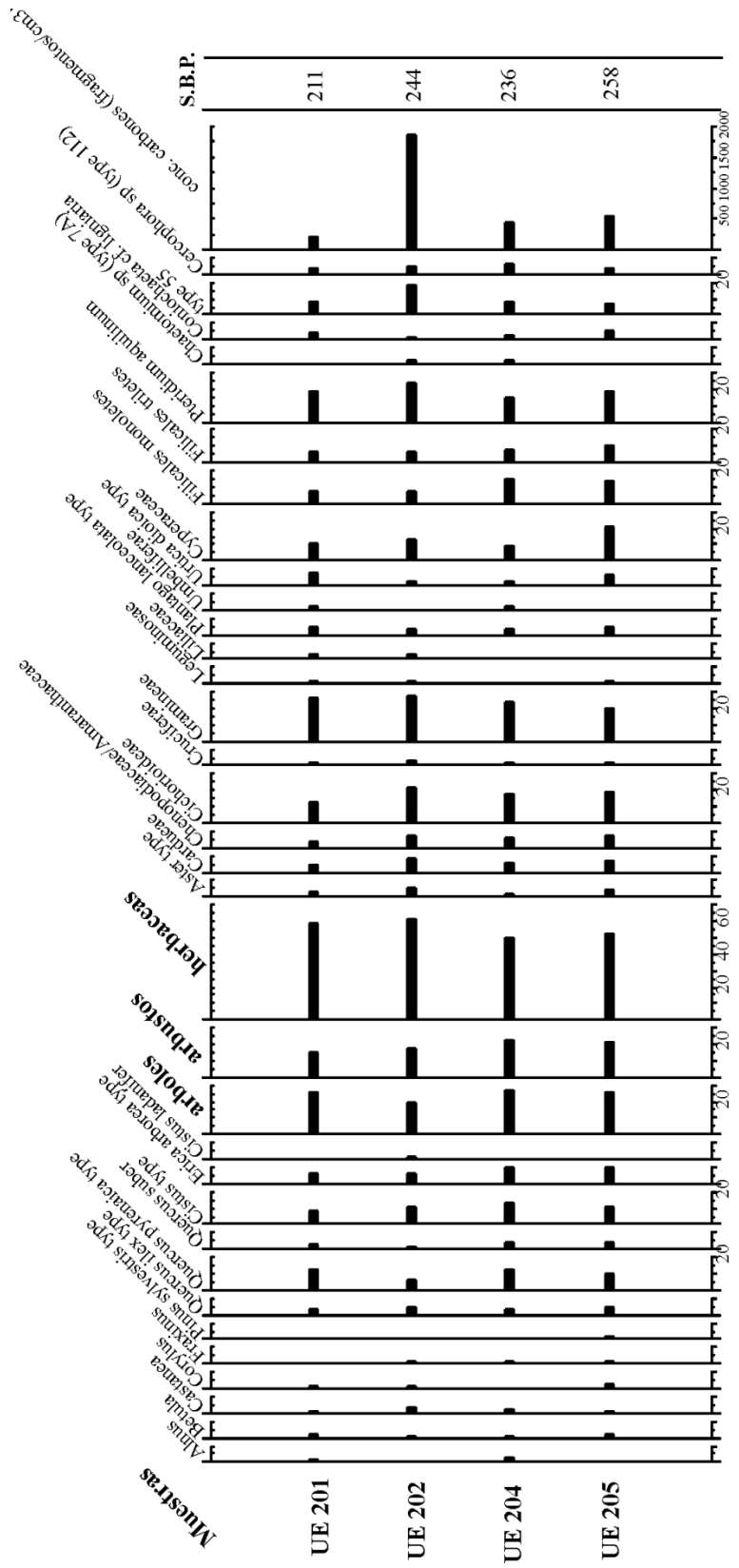

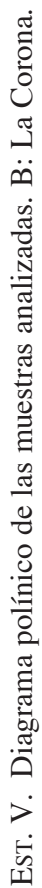




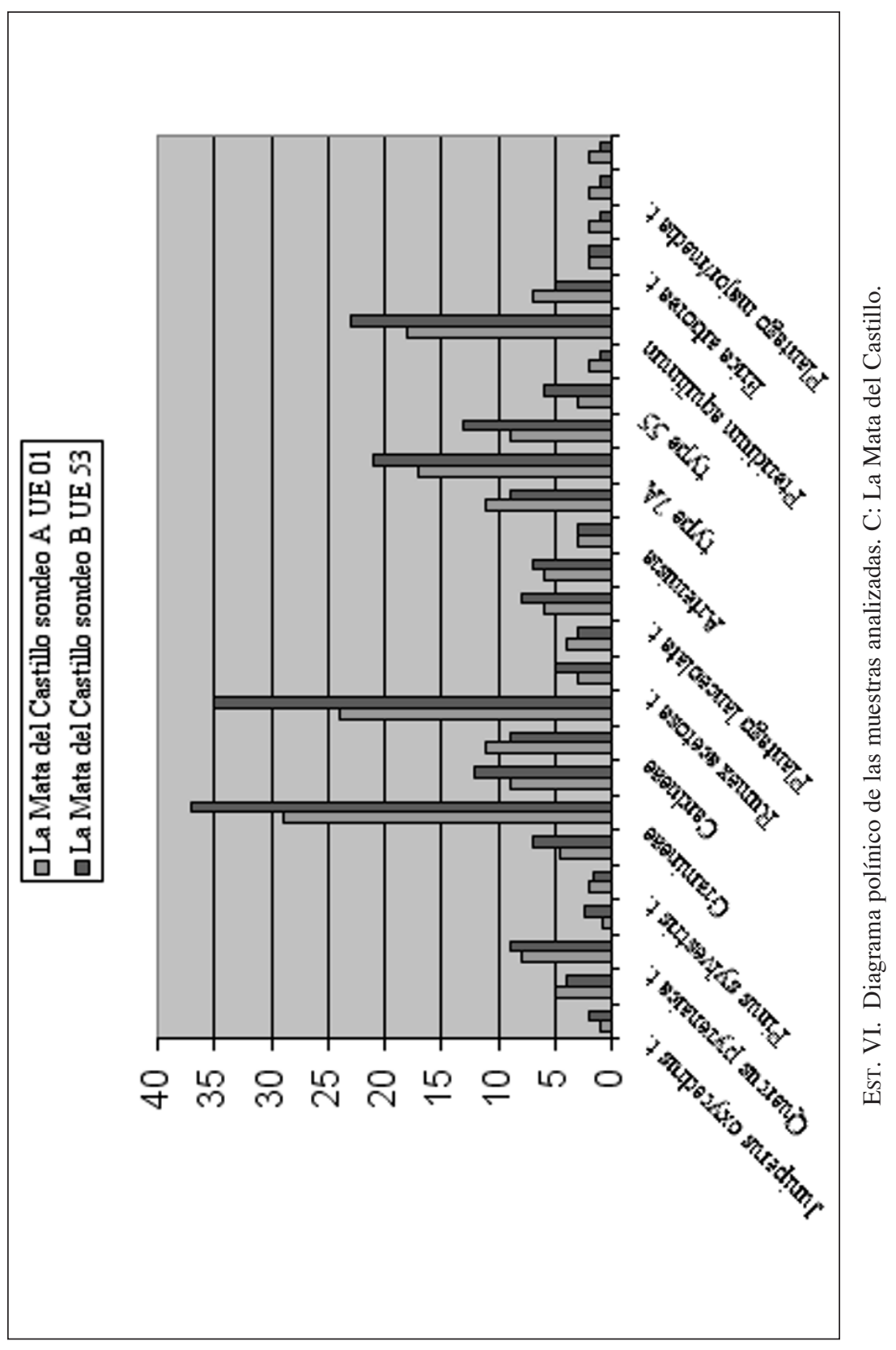




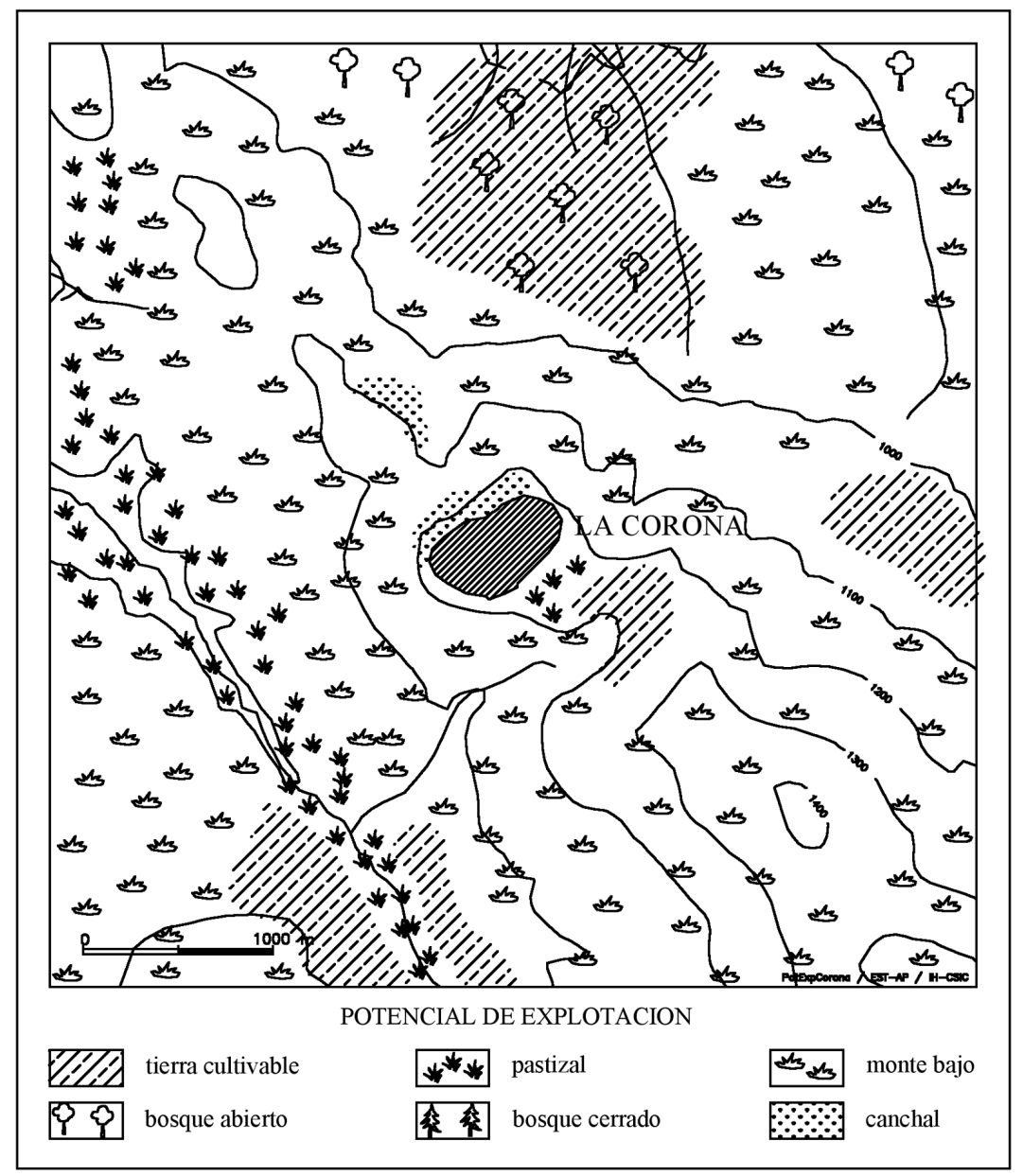

EST. VII. Situación de La Corona en su entorno y características del área inmediata de captación de recursos. 


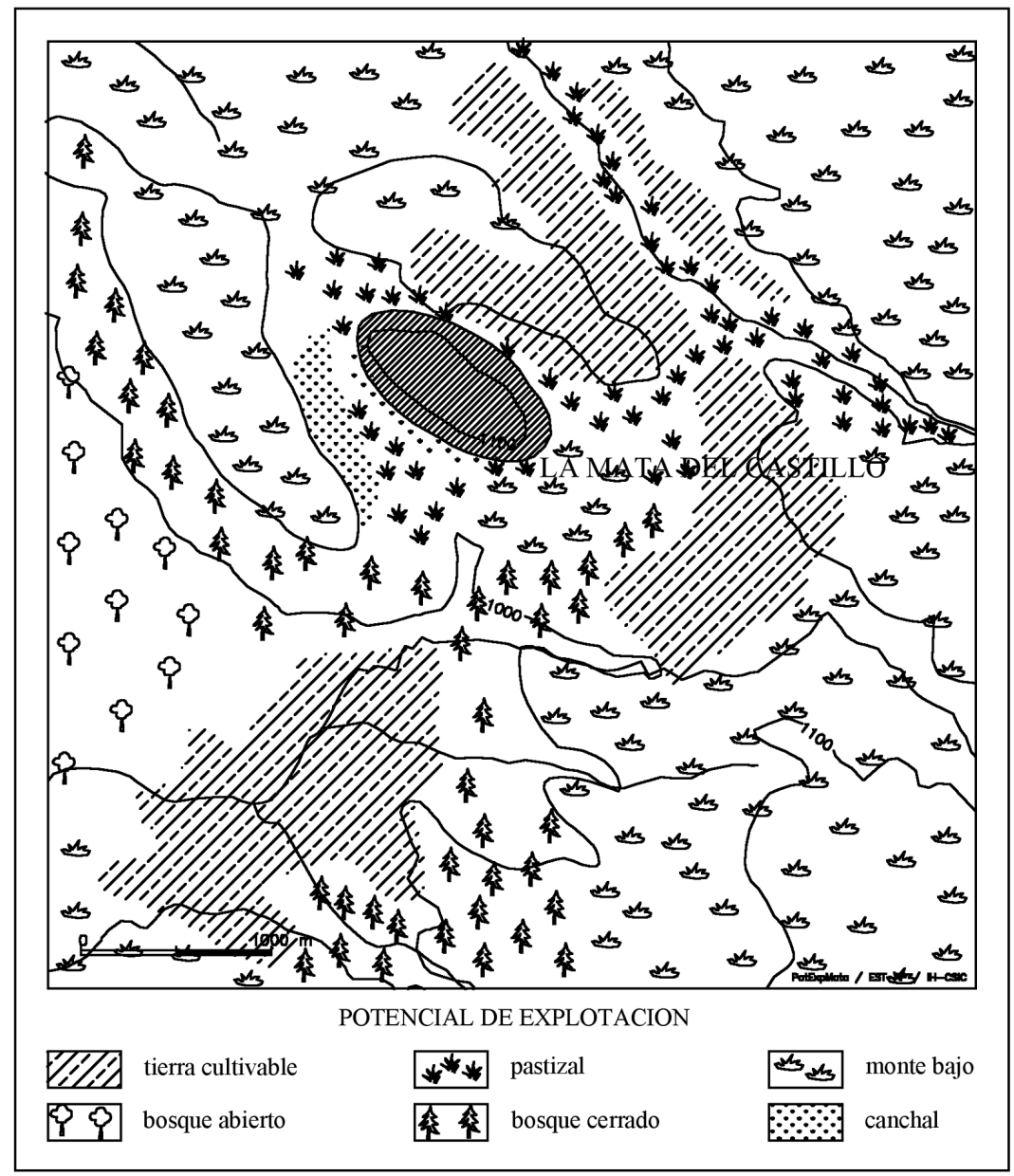

Est. VIII. Situación de La Mata del Castillo en su entorno y características del área inmediata de captación de recursos. 